\title{
Avaliação dos Serviços Prestados pela Companhia Pernambucana de Saneamento no Município de Petrolina
}

\author{
Cícero Bezerra da Silva Júnior'; Geferson Wilson da Silva; \\ Joaquim Marques Neto ${ }^{3}$ Natanael Marques da Silva ${ }^{4}$; Hesler Piedade Caffé Filho ${ }^{5}$
}

\begin{abstract}
Resumo: O presente artigo consiste no estudo da prestação de serviços públicos de abastecimento de água e esgotamento sanitário no município de Petrolina-PE, ofertada de forma descentralizada por uma sociedade de economia mista, segundo os princípios da legalidade, impessoalidade, moralidade, publicidade e eficiência, norteadores da administração pública, visando a satisfação da coletividade. O objetivo deste trabalho é avaliar a adequação dos serviços prestados pela Concessionária Companhia Pernambucana de Saneamento às condições de regularidade, continuidade, eficiência, atualidade, cortesia e modicidade de tarifas previstas na Lei $\mathrm{n}^{\circ}$ 8.987/1995. A pesquisa foi realizada de forma exploratória através de levantamento bibliográfico e aplicação de questionário, durante o período de 23 a 02 de março de 2017, a 75 moradores dos bairros centrais e periféricos de Petrolina, escolhidos de forma aleatória. Os resultados sugerem uma negligência da concessionária quanto aos quesitos pesquisados, levando ao diagnóstico de insatisfação dos moradores questionados, indicando a necessidade de intervenção pelo Poder Concedente.
\end{abstract}

Palavras-chave: Administração Pública. Concessão. Serviços Públicos. Satisfação.

\section{The adjustment of Public Services rendered by the Pernambucana Sanitation Companyin the Municipality of Petrolina}

\begin{abstract}
The present article consists in the study of the provision of public water supply and sewage services in the municipality of Petrolina-PE, offered in a decentralized manner by a mixed economy company, according to the principles of legality, impersonality, morality, publicity and efficiency, Public administration, aiming at the satisfaction of the community. The objective of this study is to evaluate the adequacy of the services rendered by Companhia Pernambucana de Saneamento to the conditions of regularity, continuity, efficiency, timeliness, courtesy and modicity of tariffs established in Law 8,987 / 1995. The research was carried out in an exploratory way through a bibliographical survey and questionnaire application, during the period from March 23 to 02 , 2017, to 75 residents living in the central and peripheral neighborhoods of Petrolina, chosen at random. The results suggest a negligence of the concessionaire regarding the queried questions, leading to the diagnosis of dissatisfaction of the residents questioned, indicating the need for intervention by the Granting Authority.
\end{abstract}

Keywords: Public administration. Concession. Public Services. Satisfaction.

\footnotetext{
${ }^{1}$ Graduando em Administração Pública pela Universidade Federal do Vale do São Francisco (UNIVASF);

${ }^{2}$ Graduando em Administração Pública pela Universidade Federal do Vale do São Francisco (UNIVASF);

${ }^{3}$ Graduando em Administração Pública pela Universidade Federal do Vale do São Francisco (UNIVASF);

${ }^{4}$ Graduando em Administração Pública pela Universidade Federal do Vale do São Francisco (UNIVASF);

5 Autor correspondente: jmarks.neto@ hotmail.com;

${ }^{5}$ Mestre em Gestão de Políticas Públicas pela Universidade Federal do Recôncavo da bahia (UFRB) e Professor do bacharelado em

Administração Pública da Universidade Federal do vale do São Francisco - UNIVASF. Contato: hesler.caffe@ univasf.edu.br.
} 


\section{Introdução}

A administração pública contemporânea também denominada de gerencial surgiu da necessidade de aperfeiçoamento da administração burocrática, ante o contexto social e político ora existente, como a crise econômica e a crise do Estado. Práticas que eram aplicadas nas organizações privadas foram adotadas pelas organizações públicas com o objetivo de desburocratizar os processos.

Segundo Mello (2015), a palavra administração tem o sentido de relação de subordinação e hierarquia. $\mathrm{O}$ autor demonstra que a palavra administrar significa não só prestar serviço ou executá-lo, como também dirigir, governar, exercer a vontade com o objetivo de obter um resultado útil; significa também traçar um programa de ação e executálo, bem como, coordenar, planejar, controlar, padronizar, organizar e executar.

Quanto ao estudo da Administração Pública, Meirelles (2003), define: em sentido formal, como o conjunto de órgãos instituídos para consecução dos objetivos do Governo; em sentido material, como o conjunto das funções necessárias aos serviços públicos em geral; na acepção operacional, como o desempenho perene e sistemático, legal e técnico, dos serviços próprios do Estado ou por ele assumidos visando a satisfação das necessidades coletivas.

A partir de uma perspectiva histórica, verifica-se que a administração pública evoluiu, sucedendo de forma complementar três modelos: Patrimonialista, Burocrática e Gerencial.

No modelo patrimonialista, que no Brasil, remonta aos tempos do Brasil Colônia, não havia uma distinção clara entre os bens públicos e particulares. A monarquia fazia uso de todo o patrimônio estatal, como se seu fosse, sem prestar contas à sociedade. Para Bresser (2001), patrimonialismo era "a incapacidade ou a relutância de o príncipe distinguir entre o patrimônio público e seus bens privados".

Os cargos e empregos públicos eram preenchidos por pessoas ligadas diretamente ao monarca ou em troca de favores. Não havia carreira de cargos efetivos. O que predominava era a livre escolha do soberano. O que caracterizava de forma marcante esse modelo era nepotismo, a corrupção, além da confusão da propriedade particular com a privada. 
O poder era concentrado nas mãos do soberano que o delegava a poucos parceiros de sua confiança, os quais o usavam de forma arbitrária, fazendo pouco caso com as necessidades básicas e sociais dos súditos, já que as decisões eram tomadas de forma discricionária e ditatorial. Assim, não havia uma organização do Estado e da Administração Púbica com o fim de garantir à sociedade as funções estatais (políticas, sociais e econômicas).

Até meados do século XIX, o patrimonialismo manteve-se ativo e predominante no Brasil. Somente com o advento da industrialização, o surgimento de grandes organizações, assim como as demandas sociais crescentes, fizeram com que os governantes procurassem novos modelos de administração capazes de atender aos anseios tanto das organizações como da sociedade em geral.

A teoria da democracia foi desenvolvida por Max Weber e trouxe um modelo de administração para o Novo Estado com a principal finalidade de combater a corrupção, o nepotismo. Esse novo modelo estava baseado em um tripé: formalidade, impessoalidade e profissionalismo. Esse tripé mostra como a administração burocrática trouxe uma visão totalmente diferente do modelo patrimonialista.

A burocracia é focada em leis, regras e normas, ou seja, há pouca discricionariedade para o administrador. Outra característica da formalidade é a padronização da comunicação interna e externa. Há um modelo formal de comunicação para ser usado de acordo com a hierarquia interna e também um modelo de comunicação para uso com pessoas e instituições externas.

A formalidade tem ainda outra característica importante que é o controle dos procedimentos, onde são estipuladas as regras que serão usadas em todos os processos das instituições ou orgãos, como exemplo, nas compras, vendas, contratação de pessoal etc. A lei 8.666/93 que institui normas para licitações e contratos é exemplo claro de controle aplicado à administração pública.

A impessoalidade no modelo burocrático traz a ideia de acabar com o tráfico de influência que havia do modelo patrimonialista. A isonomia deve estar presente no tratamento das pessoas de forma que as regras sejam aplicadas a todos de forma igualitária. Outro traço a destacar dentro do tripé impessoalidade é a meritocracia, onde as pessoas ocupam cargos e desenvolvem atividades de acordo com a sua capacidade e conhecimento e não por 
"apadrinhamento" como era no modelo patrimonialista. Vale destacar também a racionalidade apresentada no modelo burocrático, que é a tomada de decisões baseada em dados reais, objetivos e concretos e não em opiniões e desejos pessoais.

O profissionalismo dentro da burocracia mostrou a necessidade de acabar com o nepotismo. Em vez dos cargos serem ocupados por parentes em troca de favores e interesses, passaram a ser preenchidos por profissionais qualificados em cada área e com remuneração em dinheiro e não em honrarias, títulos de nobreza, etc. Assim, passou-se a valorizar os profissionais especializados, que por sua vez, passaram a ter uma carreira a seguir, o que trouxe essa ideia de valorização e bem estar além da hierarquia, ou seja, quem hoje ocupa um cargo inferior na carreira, amanhã poderá está ocupando outro de hierarquia superior, o que gera motivação.

Ainda sobre o modelo burocrático, observa-se que trouxe disfunções na prática, entre as quais podemos citar: a perda da visão global, devido a centralização e foco dos empregados voltados para solucionar os problemas da máquina estatal e não da sociedade.

Diante do contexto de crise econômica e do Estado, práticas que eram aplicadas nas organizações privadas começaram a ser levadas para as organizações públicas com o objetivo de desburocratizar os processos. Originariamente esse método começou com o modelo Inglês, que evoluiu do Gerencialismo puro, passando pelo Consumerismo ao PSO - Public Service Orientation.

O Gerencialismo foi o primeiro momento da experiência Inglesa, com a posse de Margaret Thatcher no poder, em 1979. Nessa época a grande preocupação era com a situação fiscal, uma vez que o governo passava por uma crise financeira muito séria. Assim, viu-se a necessidade do Estado deixar de atuar de forma direta em algumas áreas (telefonia, aviação, siderurgia etc), fazendo a opção pela privatização da oferta desses serviços, com objetivo de captar recursos e minimizar os gastos da máquina pública.

O segundo momento foi chamado de Consumerismo, onde a preocupação não era só com o custo, com a eficiência e com a produtividade, mas, com o cliente, que passou a ser visto como um aliado do governo, contribuindo com o pagamento dos impostos, e em contrapartida, recebia deste, serviços essenciais e de qualidade. Houve também a descentralização dos serviços, com a delegação de autoridades, o incentivo à competição 
dentro do Estado e a contratualização dos serviços públicos com foco na qualidade e efetividade.

Já o terceiro momento foi o PSO - Public Service Orientation, que era uma evolução da visão de cliente. Aqui a preocupação era direcionar o foco no cidadão, aplicando a isonomia, a transparência e a participação política através da descentralização que era vista como auxiliadora neste processo, trazendo, assim, a noção de "bem comum" à sociedade.

As principais iniciativas do modelo gerencial começaram com a mudança do foco do controle, ou seja, no modelo burocrático, o controle era focado nos processos e procedimentos de acordo com as regras e normas pré-estabelecidas, o que gerava ineficiências. Já o controle no modelo gerencial procurou retirar o foco dos processos para levá-lo aos resultados, às necessidades dos clientes. A ideia era saber se o órgão ou instituição chegou ao resultado efetivo, alcançando o objetivo esperado e não apenas se foram cumpridas normas e regras. As características principais do Modelo Gerencial foram:

$\checkmark$ Cobrança de resultados a posteriori;

$\checkmark$ Maior autonomia (financeira, material e de recursos humanos);

$\checkmark$ Definição dos objetivos a serem alcançados;

$\checkmark$ Competição dentro da máquina estatal;

$\checkmark$ Preocupação com os clientes;

$\checkmark$ Descentralização;

$\checkmark$ Incentivo à inovação;

$\checkmark$ Estrutura hierárquica mais achata e flexível.

Com a promulgação da Constituição Federal em 1988 foram definidos os princípios norteadores da Administração Pública: Legalidade, Impessoalidade, Moralidade, Publicidade e Eficiência, este último adicionado em 1998.

Conforme Mello (2010), o principio da legalidade se contrapõe com qualquer tendência de exacerbação personalista dos governantes e a todas as formas de poder autoritário. Segundo o autor, todo poder emana do povo, e os governantes são apenas representantes da sociedade. No Brasil o principio da legalidade significa que a Administração nada pode fazer senão o que a lei determina. 
Meirelles (1990. p. 81, apud MEDAUAR, 2010, p. 144) associa a impessoalidade ao princípio da finalidade, que corresponde ao atendimento do interesse público, ou seja, o administrador fica impedido de buscar outro objetivo ou de praticá-lo no interesse próprio ou de terceiros.

O objetivo desse princípio é que o administrador tenha uma conduta ética associada à honestidade, boa-fé, confiança, probidade, vedada a transgressão do senso moral da sociedade.

Para Moraes (2011), não bastará ao administrador o estrito cumprimento da legalidade, devendo ele, no exercício de sua função pública, respeitar os princípios éticos de razoabilidade e justiça, pois a moralidade constitui, pressuposto de validade de todo ato da administração.

Segundo este princípio o poder público deve agir com transparência para que os administrados tenham conhecimento dos seus atos, proporcionando a fiscalização e o controle da Gestão pública.

Meirelles (2010) também ressalta que o sigilo só é permitido no caso de segurança nacional, investigações policiais ou por interesse superior da administração, a ser preservado em processo previamente declarado nos termos das leis e decretos.

A publicidade como princípio da administração pública, abrange toda a atuação estatal, não apenas sob o aspecto de divulgação oficial de seus atos, como ainda, de propiciação de conhecimento da conduta interna de seus agentes.

De acordo com Meirelles (2010), o princípio da eficiência é o mais moderno princípio da função administrativa, exigindo resultados positivos para o serviço público e satisfatório atendimento das necessidades da comunidade, através do aproveitamento dos recursos disponíveis.

O administrador público deve atender às necessidades dos cidadãos com agilidade, presteza, eficácia, rapidez, urbanidade e neutralidade.

A Administração Pública no Brasil divide-se em direta ou indireta. Segundo Di Pietro (2015) a Administração Direta representa a prestação do serviço diretamente pelo Estado, de forma centralizada, por meio dos órgãos públicos (ministérios, secretarias e órgãos subordinados) ligados aos entes federados: União, Estados, Municípios e Distrito Federal. 
A autora ainda define a Administração Indireta como a prestação de serviço descentralizada exercida pelas autarquias, fundações, sociedades de economia mista ou empresas públicas através de delegação ou outorga.

Meirelles (2010) define o serviço público como todo aquele prestado pela Administração ou por seus delegados, sob normas e controles estatais, para satisfazer necessidades essenciais ou secundárias da coletividade, ou simples conveniências do Estado.

Mello (2015), já corrobora com a afirmação de que o Estado tanto pode prestar por si mesmo as atividades administrativas, como pode desempenhá-las por via de outros sujeitos, caso em que estará perante a chamada descentralização. Nesta hipótese ora o Estado transfere o exercício de atividades que lhe são pertinentes para particulares, ora cria pessoas auxiliares para desempenhar suas funções.

Observa-se que a Constituição Federal de 1988, no art. 175, dispõe sobre a incumbência do Poder Público, diretamente ou sob regime de concessão ou permissão, sempre através de licitação, a prestação de serviços públicos.

De acordo com a Lei 8.987/95, a concessão da prestação dos serviços públicos consiste na delegação do poder concedente, mediante licitação, na modalidade concorrência, à pessoa jurídica ou consórcio de empresas que demonstre capacidade para seu desempenho, por sua conta e risco e por prazo determinado.

Enquanto que a permissão de serviço público corresponde à delegação, a título precário, mediante licitação, da prestação de serviços públicos, feita pelo poder concedente à pessoa física ou jurídica que demonstre capacidade para seu desempenho, por sua conta e risco.

Ainda conforme esse dispositivo legal, o contrato de concessão gera uma relação triangular, pois envolve o ente público que descentraliza a prestação do serviço, a pessoa que figura como concessionária que assume a prestação desse serviço público e o usuário que arca com a contraprestação pecuniária por meio do pagamento de tarifas.

$\mathrm{O}$ art. $9^{\circ}$ da referida lei, preceitua que a tarifa do serviço público concedido será fixada pelo preço da proposta vencedora da licitação e preservada pelas regras de revisão previstas nesta lei, no edital e no contrato. Cabe ao Estado criar mecanismos para que o valor da tarifa não seja abusivo e o serviço possa estar ao alcance de toda a sociedade. 
Quanto aos danos causados a terceiros, a responsabilidade, a priori, é da concessionária ou permissionária que causou prejuízo. O Estado que delegou a prestação do serviço responderá apenas de modo subsidiário. O contrato de concessão, assim como os demais contratos administrativos, pode ser extinto por razões de inadimplemento da parte concessionária ou por razões de interesse público.

$\mathrm{O} \S 2^{\circ}$ do art. $6^{\circ}$ da mesma lei, traz a definição de que serviço adequado é o que satisfaz as condições de regularidade, continuidade, eficiência, segurança, atualidade, generalidade, cortesia na sua prestação e modicidade das tarifas.

Quanto ao saneamento básico, que constitui um conjunto de serviços, infra-estruturas e instalações operacionais de abastecimento de água, esgotamento sanitário, limpeza urbana, manejo de resíduos sólidos, drenagem e manejo das águas pluviais, a Lei 11.445/2007 estabelece que podem ser delegadas a organização, a regulação, a fiscalização e a prestação destes serviços.

Esses serviços serão fiscalizados por entidade reguladora, que editarão normas relativas às dimensões técnica, econômica e social.

No Estado de Pernambuco, com o objetivo de execução da política governamental de abastecimento de água e esgotamento sanitário, bem como de preservação e aproveitamento dos recursos hídricos, através da Lei 6.307/71 foi fundada a COMPESA - Companhia Pernambucana de Saneamento, sociedade anônima de economia mista, dotada de personalidade jurídica de direito privado, tendo como acionista majoritário o Estado de Pernambuco.

Atualmente opera em todas as regiões do Estado de Pernambuco, do litoral ao sertão, prestando serviços em 173 dos 185 municípios do Estado, incluindo o arquipélago de Fernando de Noronha.

Diante do exposto, este estudo tem como objetivo avaliar a adequação dos serviços prestados pela Concessionária Companhia Pernambucana de Saneamento às condições de regularidade, continuidade, eficiência, atualidade, cortesia e modicidade de tarifas previstas na Lei $\mathrm{n}^{\circ} 8.987 / 1995$.

\section{Métodos}


Conforme aponta Tartuce (2006), o método científico compreende um conjunto de dados iniciais e um sistema de operações ordenadas adequadas para a formulação de conclusões, de acordo com certos objetivos predeterminados.

Quanto à abordagem, adotou-se a pesquisa qualitativa buscando o porquê de uma realidade, exprimindo o que convém ser feito sem quantificar ou submeter à prova de fatos.

A fim de obter uma maior familiaridade ou compreensão do problema, a pesquisa ocorreu de forma exploratória, através de levantamento bibliográfico e aplicação de questionário, composto por 7 questões, disponibilizado em formato eletrônico pela internet, viabilizado pela plataforma Googledcs, no período 23 de fevereiro a 02 de março do ano de 2017, a 75 residentes de bairros centrais e periféricos da cidade de Petrolina, escolhidos de forma aleatória.

Segundo informações disponibilizadas pelo IBGE - Instituto Brasileiro de Geografia e Estatística, a população estimada de Petrolina em 2016 era de 337.683 habitantes, enquanto que sua área territorial é de $4.561,872 \mathrm{~km}^{2}$.

\section{Resultados e discussões}

Através da aplicação do questionário, buscou-se inicialmente o conhecimento sobre a variável regularidade no fornecimento de água e na manutenção e reparo da rede de esgotamento sanitário. Conforme o gráfico 1, os números revelaram que a maioria, $56 \%$ dos respondentes, demonstraram pouca satisfação no atendimento desses serviços, por sua vez, $26,7 \%$, encontram - se totalmente satisfeitos.

\section{Gráfico 1}




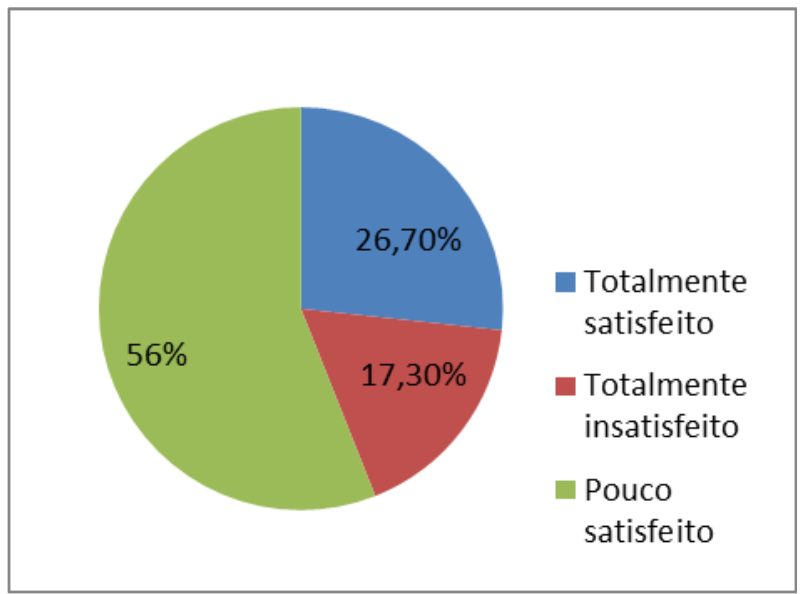

Fonte: Elaborada pelos autores

Quanto ao valor das tarifas cobradas pela COMPESA, consoante com o gráfico 2, um percentual significativo de $94,7 \%$ dos questionados, julgam-nas como abusivas.

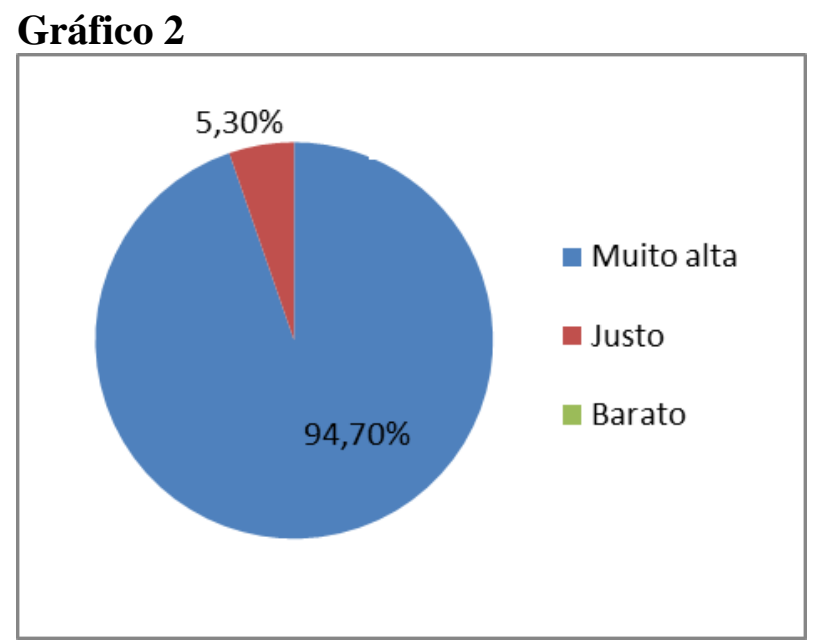

Fonte: Elaborada pelos autores

No que se refere ao prazo médio de atendimento de reclamações sobre os serviços oferecidos pela concessionária, verificou-se que $45,3 \%$ foram atendidos no intervalo de 1 e 2 dias, entretanto para $28 \%$ dos respondentes há uma espera de mais de uma semana como se vê no gráfico 3.

\section{Gráfico 3}




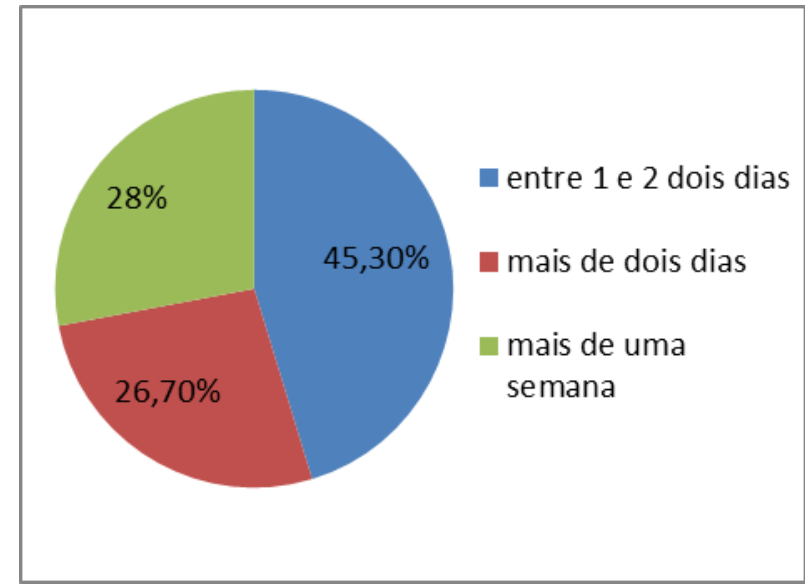

Fonte: Elaborada pelos autores

Sobre o aspecto da qualidade do atendimento dos funcionários da COMPESA, $40 \%$ dos entrevistados avaliaram como péssimo, enquanto que somente um percentual de 5,3\% afirmaram ser excelente, conforme apresentado no gráfico 4.

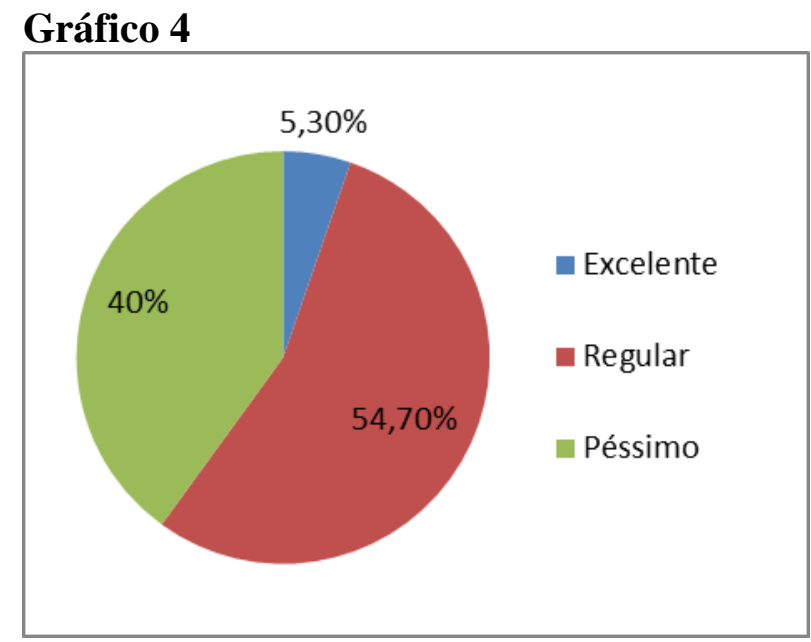

Fonte: Elaborada pelos autores

A respeito da qualidade da água fornecida pela COMPESA, 60\% dos respondentes avaliaram como tolerável, enquanto $24 \%$ julgam ruim, de acordo com o gráfico 5.

\section{Gráfico 5}




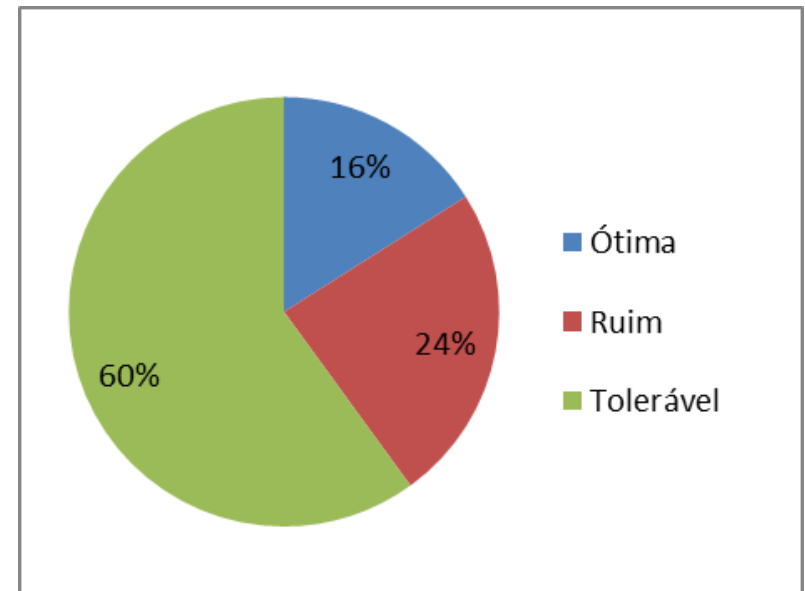

Fonte: Elaborada pelos autores

Sobre trabalhos de conscientização do uso da água através de campanha realizada pela COMPESA, 74,7\% demonstraram que não tinham conhecimento como se vê no gráfico 6 .

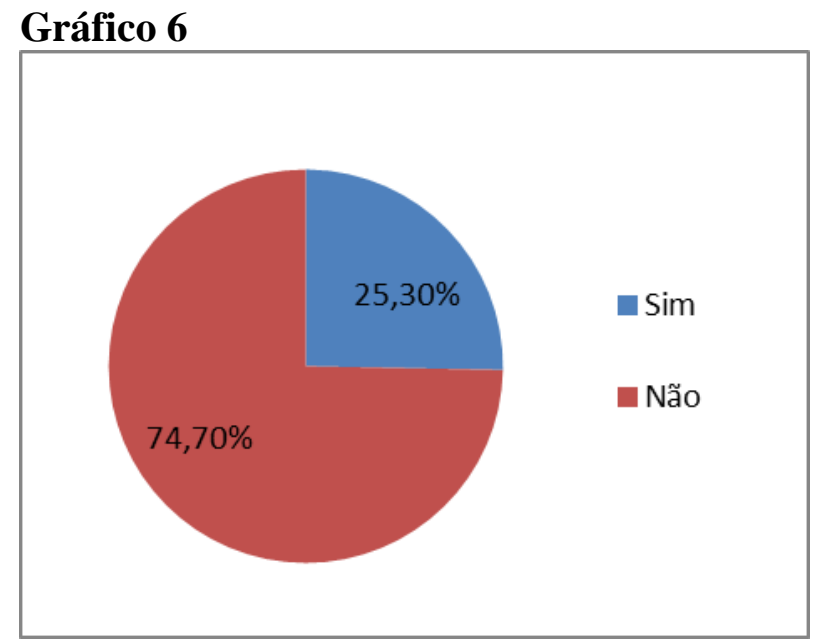

Fonte: Elaborada pelos autores

Além das questões objetivas, foi dada a oportunidade, aos respondentes do questionário, para que comentassem de forma subjetiva e livre sobre pontos fortes e fracos desse serviço público prestado pela concessionária COMPESA, conforme transcrições abaixo:

$\checkmark$ "Como moro na Cohab 5 (bairro de classe média/alta) não temos muitos problemas como nos bairros mais pobres."

$\checkmark$ "Uma vez que pagamos tão caro, pelo Saneamento Básico em Petrolina, deveríamos ter um Serviço de melhor qualidade!" 
$\checkmark$ "Falta compromisso com a população, que está em dias com sua obrigações $e$ pouca coisa é resolvida, os problemas se repetem com muita frequência."

$\checkmark$ “A qualidade do saneamento é um problema sério em Petrolina... Tubulações antigas e sem manutenção que estouram sempre! A falta de água é mais pontual, somente em alguns bairros, no meu não tem problemas quanto a falta de água, mas a qualidade eu não confio, só tomo água mineral."

$\checkmark$ "Que ultimamente aqui no meu bairro, além de faltar água todos os dias, quando chega nas torneiras sai mais ar do que agua, com certeza deve contar no hidrômetro como se fosse água."

$\checkmark$ "Situação crítica no bairro onde moro, Antonio Cassimiro 1. Esgotos estourados a muito tempo, um a 4 meses e outro a quase 3 anos."

$\checkmark$ "Não sei se é só no bairro que moro, mas quando chove, quase sempre falta água. Referente a saneamento não funciona nunca."

$\checkmark$ "Só está precisando melhorar o esgoto mesmo."

$\checkmark$ "Gostaria que diminuísse os esgotos estourados da Cidade."

$\checkmark \quad$ "Antes de ser despejado no rio, o esgoto, obrigatoriamente, deveria ser tratado. A orla de Petrolina possui encanamentos com lama preta despejada diretamente no rio, na orla 2 essa realidade é facilmente percebida."

$\checkmark$ "Se não fosse o descaso dos esgotos estourados e as taxas abusiva de cobranças de pessoas dos bairros que não estão recebendo água nas suas casas más recebe o papel para pagar. Eu diria que a nossa cidade tem uma qualidade de demanda de primeiro mundo."

\section{Conclusões}

Conforme os resultados obtidos através da aplicação de questionário, associado ao conhecimento adquirido através de pesquisas bibliográficas, verifica-se que a resposta sobre a avaliação dos serviços prestados pela Companhia Pernambucana de Saneamento no município de Petrolina foi alcançada.

A partir da definição de serviço adequado apresentada pela Lei 8.987/95, como aquele que satisfaz as condições de regularidade, continuidade, eficiência, segurança, atualidade, generalidade, cortesia na sua prestação, modicidade das tarifas, observou-se que os usuários questionados, consideraram que a concessionária em estudo, tem negligenciado em alguns quesitos, deixando-os insatisfeitos quanto à adequação dos serviços por ela oferecidos.

Quanto à regularidade e continuidade no fornecimento de água e na manutenção de reparo da rede de esgotamento sanitário, foram avaliadas como pouco satisfatória por $56 \%$ dos usuários questionados. Nota-se que, apenas um percentual de 26,7\% daqueles, consideraram satisfeitos.

Ao observar a modicidade das tarifas, 94,7\% dos moradores questionados, avaliou abusivo o valor das tarifas cobradas pela concessionária. 
No que se refere à eficiência na resolução das reclamações dos clientes, verificou-se que ainda há uma espera significativa, tendo em vista que $28 \%$ destes aguardam por mais de uma semana pelo atendimento.

Sobre o tratamento cortês e urbano prestado pelos funcionários da COMPESA foi avaliado em $94,7 \%$ como regular ou péssimo.

Ao analisar a preocupação contemporânea sobre a escassez de água, no item atualidade, verificou-se que a COMPESA não tem investido na adoção de medidas de conscientização do uso racional da água, pois $74,7 \%$ desconhecia alguma campanha em prol desse objetivo, promovida por esta concessionária.

Diante da realidade averiguada, observou-se que a prestação do serviço público no que se refere ao fornecimento de água, implantação e manutenção da rede de esgotamento sanitário pela COMPESA, não tem alcançado a plena satisfação aos seus usuários, indicando a necessidade de aprimoramento através de intervenções do Poder Concedente, haja visto que, segundo os dispositivos legais, as concessões sujeitar-se-ão à fiscalização do responsável pela delegação com a cooperação dos usuários.

\section{Referências}

ABRUCIO, F. L. O impacto do modelo gerencial na Administração Pública: Um breve estudo sobre a experiência internacional recente. Caderno ENAP n¹0, 52. 1997.

BRESSER P. L. C. Do Estado Patrimonial ao Gerencial. Em W. e. Pinheiro, Brasil: um século de transformações (pp. 222-259). São Paulo: Cia das Letras. 2001.

BRASIL. Constituição da República Federativa do Brasil de 1988. Disponível em: <http://www.planalto.gov.br/ccivil_03/constituicao/constituicao.htm>. Acesso em 12 maio 2017.

BRASIL. Lei $\mathbf{N}^{\mathbf{0}} \mathbf{8 . 9 8 7}$, de 13 de fevereiro de 1995. Dispõe sobre o regime de concessão e permissão da prestação de serviços públicos previsto no art. 175 da Constituição Federal, e dá outras providências. Disponível em: < http://www.planalto.gov.br/ccivil_03/ leis/L8987cons.htm>. Acesso em 30 maio 2017.

BRASIL. Lei $\mathbf{N}^{\mathbf{1}}$ 11.445, de 5 de janeiro de 2007. Estabelece diretrizes nacionais para saneamento básico. Disponível em: < http://www.planalto.gov.br/ccivil_03/_ato20072010/2007/lei/111445.htm>. Acesso em 25 maio 2017. 
COMPESA. Institucional. Disponível em: 〈http://www.servicos.compesa.com.br〉. Acesso em 28 de maio de 2017.

GIL, A. C. Métodos e Técnicas de Pesquisa Social. 5 ed. São Paulo: Atlas, 1999.

IBGE. Populacao de Petrolina. Disponível em: $<$ http://cidades.ibge.gov.br/xtras/perfil.php?lang=\&codmun=261110\&search=pernambuc opetrolina $>$. Acesso em: 31 de maio de 2017.

MEIRELLES, Hely Lopes. Direito Administrativo Brasileiro. 36. ed. São Paulo: Atual, 2010.

MELlO, Celso Antônio Bandeira de. Curso de Direito Administratico, $32^{a}$ edição. São Paulo: Malheiros Editores, 2015.

MORAES, Alexandre de. Constituição do Brasil Interpretada e Legislação Constitucional. 8. ed. São Paulo: Atlas, 2011.

PERNAMBUCO. Lei No6.307, de 29 de julho de 1971. Autoriza o Poder Executivo a constituir a Companhia Pernambucana de Saneamento (COMPESA) e dá outras providências. Disponível em: <http://www.servicos.compesa.com.br/legislacao/>. Acesso em 25 de maio de 2017.

PIETRO, Maria Sylvia Zanella Di. Direito Administrativo, 28. ed. São Paulo: Atlas, 2015.

TARTUCE, T. J. A. Métodos de pesquisa. Fortaleza: UNICE - Ensino Superior, 2006. Apostila.

\section{Como citar este artigo (Formato ABNT):}

SILVA JÚNIOR, Cícero B.; SILVA, Geferson W.; MARQUES NETO, Joaquim; SILVA, Natanael M.; CAFFÉ FILHO, Hesler P. Avaliação dos Serviços Prestados pela Companhia Pernambucana de Saneamento no Município de Petrolina. Id on Line Revista Multidisciplinar e de Psicologia, Maio de 2017, vol.11, n.36, p.37-51. ISSN: 1981-1179.

Recebido: 04.06.2017

Aceito: 09.06. 2017 